\title{
Undertaking research with children and young people
}

\section{Alison Twycross, ${ }^{1}$ Joanna Smith ${ }^{2}$}

10.1136/eb-2017-102619

${ }^{1}$ Children's Nursing, School of Health and Social Care, London South Bank University, London, UK

${ }^{2}$ Children's Nursing, School of Healthcare, University of Leeds, Leeds, UK

\section{Correspondence to:}

\section{Dr Alison Twycross,}

Children's Nursing, School of Health and Social Care, London South Bank University, London SE10AA, UK; alisontwycross@ hotmail.com
In the previous edition of Evidence-Based Nursing, 'the ethical context of nursing research', the role of the nurse researcher in respecting and ensuring the welfare of participants was highlighted. ${ }^{1}$ Historically, children and young people (CYP) have been excluded from participating in research because of tensions between developing a sound knowledge base for interventions, care and service delivery and the need to protect them. ${ }^{2}$ Involving CYP in the planning, participation and dissemination of research will ensure that the research undertaken is relevant to their needs and considers their overall well-being. While safeguarding the child or young person is paramount, Articles 12 and 13 of the United Nations' Convention on the Rights of the Child highlight children's rights to participate, articulate an opinion and freedom of expression in matters that affect them. ${ }^{3}$ CYP should be provided with opportunities to voice their views and concerns and be involved in decisions. This article will focus on three issues: involving CYP in planning research, information provision and the legal and moral considerations when seeking consent from CYP.

\section{Involving CYP in planning research}

It is now recognised that, whenever possible, CYP should be involved in all stages of the research process, from planning, data collection and analysis, and dissemination. Several organisations facilitate and support CYP's involvement in research such as Generation R (http:// generationr.org.uk/about/), a national advisory group made up of local youth forums across England. Groups typically consist of 10-15 members, aged 8-19 years, meeting every 6 weeks with their views feeding into the design and delivery of research. The National Children's Bureau also have Young Research Advisers (YRAs), aged 12-21 and 25 years for disabled young people (http://www.ncb.org. uk/what-we-do/how-we-work/research/involving-childrenyoung-people-research). The YRAs are involved in several activities including:

- Developing research questions and objectives;

- Engaging young people as research participants;

- Collecting information in ways which are age-appropriate;

- Analysing, interpreting and writing up research findings from the perspective of young people.

Additional information and resources about involving CYP in research can be found at: http://www.invo. org.uk/find-out-more/how-to-involve-people/involvingchildren-and-young-people/.

There is general agreement that it is good practice to pay travel expenses for participants and family members ${ }^{4} 5$ and that when possible, these should be paid in advance. Although payment for attending advisory forums is recommend, incentives or payments to participate in research studies are more controversial. A guidance document on Reward and recognition for children and young people involved in research is available at: http:// www.invo.org.uk/wp-content/uploads/2016/04/INVOLVE CYPrewardandrecognitionFinalApril2016.pdf.

Paying children or offering an inducement to take part in clinical trials is illegal. For other types of research, it is worth considering asking the CYP involved what reward would be appropriate, as financial reward may not be the most appropriate. If incentives or rewards are used, they must be outlined in the ethical applications and included in study information and when obtaining consent. A token of thanks, such as a book token or gift voucher for older children or a dip in a treasure bag full of goodies, for younger children offered following participation in research does not require, including in the ethical process.

\section{Information provision}

Appropriate information about a study and what is expected from participants is a perquisite for all research. In the context of CYP, the type and format of study information must be appropriate to their age and stage of development. Key to helping CYP have sufficient information to consent to taking part in a research study is the design of participant information leaflets. It is good practice to involve CYP in designing participant information leaflets, which should consider:

- Ensuring the leaflet content is clear, free from ambiguity and written at a level suitable for a range of reading abilities. The readability index can be calculated using tools such as the Gunning Fog index (http://gunning-fog-index.com);

- Pictures or clipart can be used to increase engagement, but these must be appropriate to the child's development, prior learning and the setting;

- Information leaflets need to include the information required for informed consent as set out by the Health Research Authority (HRA)-see: http://www. hra-decisiontools.org.uk/consent/examples.html. This might mean being creative in the way the researcher phrases the question or provide the information, otherwise the young child might not fully understand the information provided.

\section{Obtaining consent from CYP}

Obtaining consent to participate in research is a requirement to fulfilling healthcare ethics committee and research governance requirements.

'Informed consent is an ongoing agreement by a person to receive treatment, undergo procedures or participate in research, after risks, benefits and alternatives have been adequately explained to them. ${ }^{6}$

CYP who are competent to understand the purpose, risks and benefits of the research should be asked for their consent to participate in research. However, it is 
considered best practice to talk to parents about the research study first and seek their permission to approach their child. Involving parents may occasionally be inappropriate, for example, research about teenage pregnancy, risk-taking behaviours, the impact of neglect or abuse or sexual health issues.

CYP can consent to care and care interventions if they are capable of choosing between alternative courses of action. ${ }^{7}$ In England, Wales and Northern Ireland, children under the age of 16 years can give their consent to take part in a research study, without parental consent, if they satisfy the criteria of Gillick competence and they:

- Fully understand the implications of taking part of the study, including the risks associated with participating;

- Have sufficient maturity to understand the nature, purpose and likely outcome of the proposed research.

Similar provision is made in Scotland by The Age of Legal Capacity (Scotland) Act $1991 .^{8}$

\section{Box 1 Key principles for gaining informed consent from children}

- If children are competent, informed consent should be obtained from them before starting data collection

- No pressure or coercion should be applied or implied, eg, emotional manipulation, bribery/inducements, making something else conditional on consent

- Parents should be involved in the process of gaining consent wherever possible and in all cases where a child is not yet competent

- Consent should be considered a dynamic and ongoing process and so needs to be regularly reaffirmed

- Consent should reconfirmed if a child is upset or appears uncomfortable during data collection

- CYP need to be reminded of their right to stop at any stage and provided with very easy methods to do so

- A child's refusal to participate/continue in research should be respected

- CYP should be made aware that refusing to participate, or withdrawing from the research, will have no impact on other decisions made about them

- Researchers must remember that participation in research is voluntary, and should only be undertaken by those with full understanding of what is involved and what to expect
For very young children, or children not deemed competent to provide consent, assent should be obtained from the child, in addition to consent from a parent or legal guardian. When a child agrees to take part in a study, assent should be treated in the same way as consent and if the child later wishes to withdraw from the study, their wishes should be respected. However, the European Union Clinical Trials Directive (2001/20/EC) for clinical trials states that the informed consent of the parents must be obtained before a minor can take part in a clinical trial, but minors should be given information about the study and that their refusal to take part should be respected. The key principles for obtaining information consent from children are outlined in box 1 .

It can be difficult to gauge how much a child or family member has understood about your research project. Just asking them whether they have understood inevitably receives a 'yes' answer, but there are ways that a researcher can assess a child's knowledge and understanding. ${ }^{9}$ A child's understanding can be assessed by:

- Listening to the sorts of questions a child asks about the practical implications of a study;

- Listening to their expressions of hopes and fears;

- Being alert to cues where they are seeking reassurance about what will happen during procedures.

Understanding can be assessed using games such as word searches or puzzles, true or false questionnaires and activity boards.

In conclusion, CYP should be encouraged and supported to be involved in research though identifying research priorities to participating in research if healthcare and services is relevant to their needs.

Twitter Follow Alison Twycross @alitwy and Joanna Smith @josmith175

Competing interests None declared.

Provenance and peer review Commissioned; internally peer reviewed.

\section{References}

1. Heale R, Shorten A. Ethical context of nursing research. Evid Based Nurs 2017;20:7.

2. Spriggs M, Caldwell PH. The ethics of paediatric research. J Paediatr Child Health 2011;47:664-7.

3. Newell P. The united nations convention and children's rights in the UK. London: National Children's Bureau, 1993.

4. British Sociological Association. Statement of ethical practice. London: BSA, 2004.

5. National Children's Bureau. Guidelines for research with children and young people. London: NCB, 2011. https://www.nfer.ac.uk/ schools/developing-young-researchers/NCBguidelines.pdf

6. Royal College of Nursing. Informed consent in health and social care research: RCN guidance for nurses. London: RCN Publishing, 2005:3.

7. Department of Health. Seeking consent: working with children. London: Department of Health, 2001.

8. Medical Research Council. MRC ethics guide: medical research involving children. London: MRC, 2004.

9. Alderson P, Montgomery J. Health care choices: making decisions with children. London: Institute for Public Policy Research, 2001. 